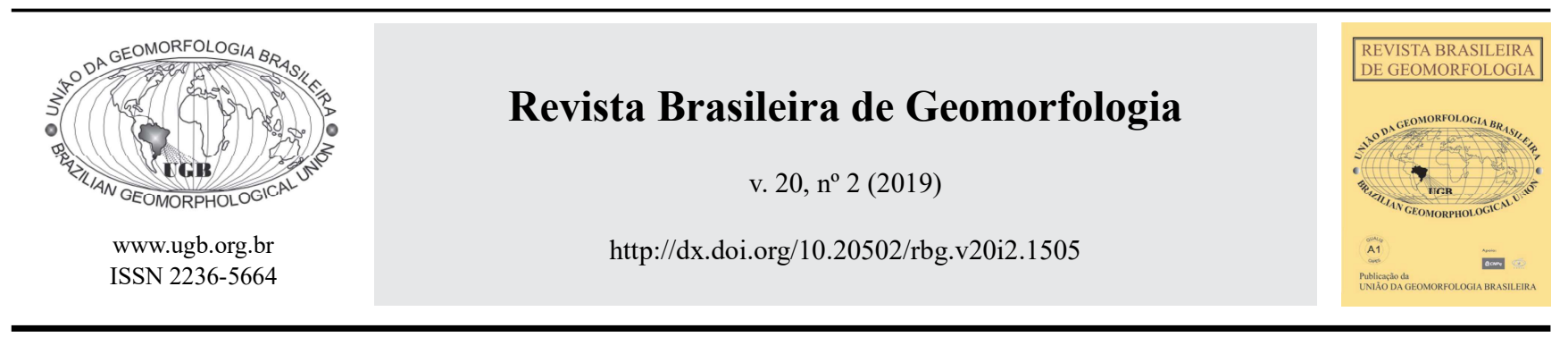

\title{
ANÁLISE MORFOLÓGICA E MORFOMÉTRICA DAS SUB-BACIAS DOS RIOS CASCATA E TINTO, LITORAL NORTE DO ESTADO DA PARAÍBA - BRASIL
}

\author{
MORPHOLOGICAL AND MORPHOMETRIC ANALYSIS OF THE \\ CASCATA AND TINTO RIVERS SUB-BASINS, NORTHERN COAST OF \\ THE PARAÍBA STATE - BRAZIL
}

\author{
Ivanildo Costa da Silva \\ Departamento de Geociências, Universidade Federal da Paraíba \\ Campus I, Bloco B, Cidade Universitária, João Pessoa, Paraíba. CEP 58.059-900. Brasil \\ E-mail:ivan13silva@yahoo.com.br
}

Max Furrier

Departamento de Geociências, Universidade Federal da Paraíba Campus I, Bloco B, Cidade Universitária, João Pessoa, Paraíba. CEP 58.059-900. Brasil E-mail: max_furrier@hotmail.com

Informações sobre o Artigo

Recebido (Received):

05/08/2018

Aceito (Accepted):

$22 / 12 / 2018$

\section{Palavras-chave:}

Geomorfologia; Morfometria; Tectônica.

Keywords:

Geomorphology; Morphometry; Tectonics.

\section{Resumo:}

A presente pesquisa objetiva analisar parâmetros morfológicos e morfométricos do relevo e da rede de drenagem nas sub-bacias hidrográficas dos rios Cascata e Tinto, no litoral Norte do Estado da Paraíba, para detectar possíveis contribuições da estrutura geológica e da atividade tectônica em suas configurações. As análises foram realizadas com o auxílio do Modelo Digital do Terreno (MDT) e os mapas de altimetria e declividade, todos gerados no Software SPRING 5.4.3, a partir de dados extraídos de cartas topográficas na escala de 1:25.000. Para a análise morfométrica foram aplicados os índices Relação Declividade/Extensão (RDE), o índice Razão Fundo/Altura de Vale (RFAV) e o Fator Assimétrico (FA). As interpretações geológicas foram baseadas em mapeamentos geológicos recentes e em seus respectivos relatórios técnicos, além de trabalho de campo. A subbacia Rio Cascata apresenta um basculamento acentuado para o lado direito, onde estão localizados seus canais tributários mais desenvolvidos. O seu canal principal apresenta uma inflexão que modifica bruscamente sua direção de NESO para N-S, anomalias interpretadas como sinais contundentes da atuação da atividade tectônica. A sub-bacia do Rio Tinto apresenta canais bem entalhados em forma de $\mathrm{V}$ e basculamento para sua margem esquerda. Seu canal principal apresenta inflexões que obedecem às direções de falhas geológicas descritas nos mapas geológicos utilizados neste trabalho. Esses fatos são evidências da influência estrutural e da atividade tectônica na configuração do relevo e da rede de drenagem, que foram corroborados pelos resultados obtidos com a aplicação dos índices morfométricos. 


\begin{abstract}
:
The present study aims to analyze morphological and morphometric parameters of the relief and drainage network in the watersheds of the Cascata and Tinto rivers, in the northern coast of Paraíba State, to detect possible contributions of the geological structure and tectonic activity in its configurations. The analyzes were carried out with the aid of the Digital Terrain Model (DTM) and the altimetry and slope maps, all generated in the SPRING 5.4.3 Software, from data extracted from topographic charts in the 1: 25,000 scale. For the morphometric analysis, the indexes Slope vs Length (SL), Ratio of Valley-Floor width to Valley Height (Vf) and Asymmetric Factor (AF) were applied. Geological interpretations were based on recent geological mappings and their respective technical reports as well as field work. The watershed of the Cascata River presents a sharp tip to the right side, where its most developed tributary canals are located. Its main channel presents an inflection that abruptly modifies its direction from NE-SW to N-S, anomalies interpreted as conclusive signs of the performance of tectonic activity. The watershed of the Rio Tinto offers well-carved channels V-shaped and tilt to the left bank. Its main channel presents inflections that obey the directions of geological faults described in the geological maps used in this work. These facts are evidences of the structural influence and the tectonic activity in the configuration of the relief and the drainage network, which were corroborated by the results obtained with the application of morphometric indices.
\end{abstract}

\section{Introdução}

O principal objetivo desse artigo é verificar através da análise de alguns parâmetros morfológicos e morfométricos do relevo e da rede de drenagem, apoiado em estudos prévios da estrutura geológica, possíveis atuações de eventos tectônicos ou controle estrutural na configuração do relevo e da rede de drenagem, das sub-bacias hidrográficas dos rios Cascata e Tinto, no Litoral Norte do Estado da Paraíba.

Alguns importantes estudos de cunho morfoestrutural e tectônico que se utilizaram de parâmetros morfológicos e/ou morfométricos já foram elaborados no litoral do Estado da Paraíba, a exemplo de Furrier et al. (2006), para todo litoral, com uma abordagem mais abrangente; Andrades Filho (2010) e Bezerra et al. (2014) na parte litorânea central, na bacia do rio Paraíba e Barbosa (2013) na região de Jacumã, litoral sul do Estado. Todos esses estudos, além dos de Rossetti et al. (2011a) e Rossetti et al. (2011b), apresentaram resultados com diversas evidências da influência estrutural e da atuação da atividade tectônica na configuração do relevo e da rede de drenagem.

Essas evidências carecem de mais estudos para serem melhor compreendidas dentro dos contextos geomorfológico/estrutural e geológico/tectônico, sobretudo, da área de estudo, visto que a região em questão está inserida na Província Costeira brasileira, entendida pela geologia como de margem passiva, apregoada no passado como completamente estável, mas que atualmente pesquisas vêm demonstrando que essa estabilidade é apenas relativa.

$\mathrm{Na}$ margem norte do rio Mamanguape, onde está inserida a sub-bacia do rio Tinto, são raros os trabalhos de geomorfologia estrutural que utilizaram a morfometria como suporte metodológico. No âmbito da geologia, Hessel e Barbosa (2005) afirmaram que essa área é uma das menos conhecidas das bacias costeiras do Brasil. Mabesoone e Alheiros (1993) salientaram que essa região representa o último elo de conexão terrestre entre os continentes americano e africano. Além disso, atribuíram a escassez de pesquisas nesse setor à inexistência de combustíveis fósseis, o que acabou não despertando interesse em investimentos na área.

Os rios Cascata e Tinto são afluentes do baixo curso do rio Mamanguape, respectivamente, das suas margens direita e esquerda (Figura 1). Eles apresentam diferenças notáveis nas suas configurações morfológicas, que podem estar relacionadas a conspícua variação de altitude observada inicialmente por Furrier et al. (2014) entre os interflúvios direito e esquerdo do rio Mamanguape.

O material cartográfico necessário para a análise morfológica foi elaborado através dos dados extraídos de 6 cartas topográficas com escala 1:25.000, as quais abrangem a área onde as duas sub-bacias estão inseridas. As cartas topográficas foram publicadas pela Superintendência de Desenvolvimento do Nordeste (SUDENE), em 1974. 


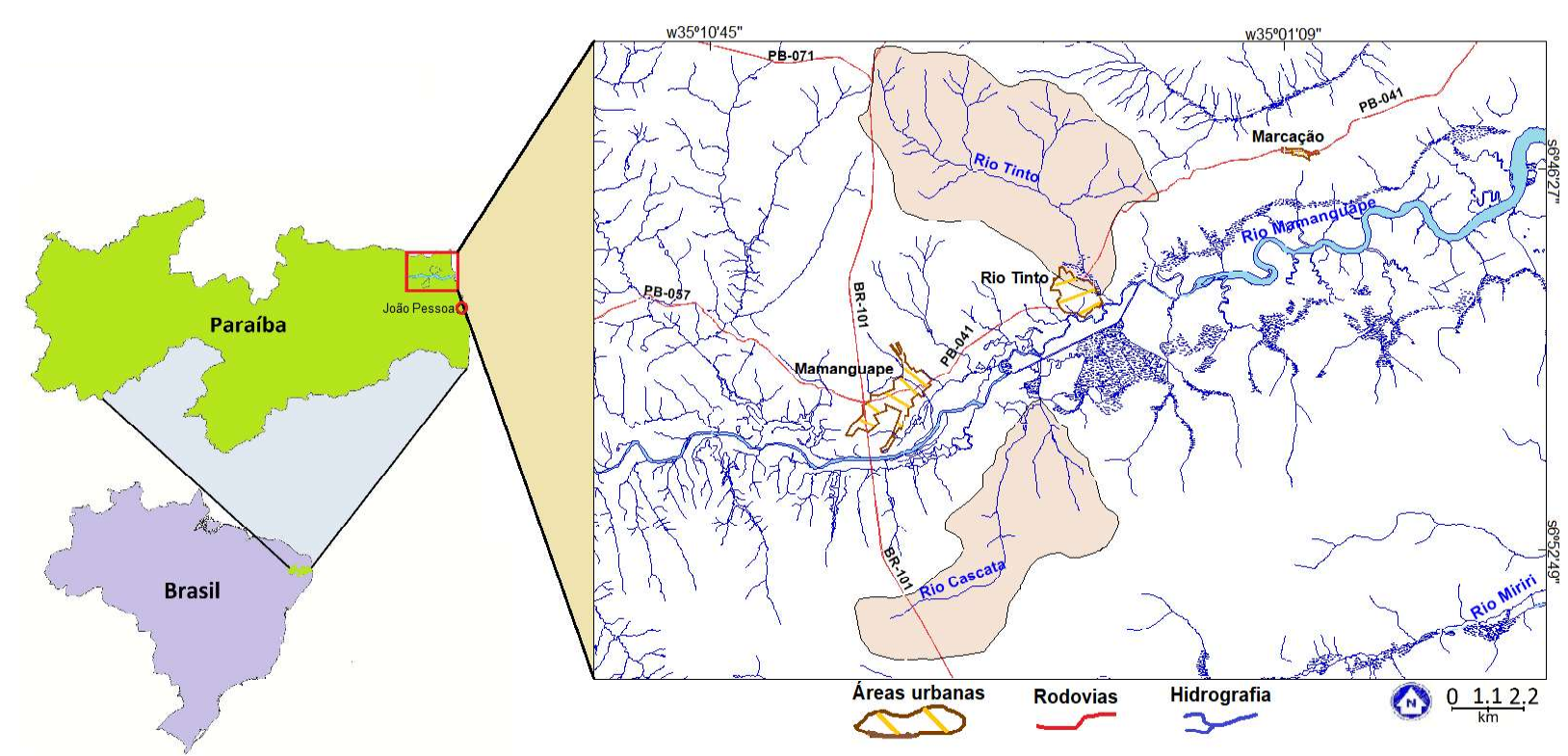

Figura 1 - Localização geográfica das sub-bacias estudadas (Adaptado de Guimarães e Bittar, 2014).

Essas cartas apresentam curvas de nível com equidistância de 10 metros e já demonstraram oferecer grande precisão nos mapas gerados em trabalhos anteriores (SILVA, 2014; LIMA, 2016), tanto no modelado do relevo quanto na relação entre o relevo e a hidrografia, apresentando resultados melhores e mais precisos do que os obtidos com as imagens Shuttle Radar Topography Mission (SRTM) com resolução de $30 \mathrm{~m}$.

Soares Neto (2015) reforça que o uso de Modelos Digitais de Elevação (MDEs) obtido pela missão SRTM pode ser considerado razoável para análises em escalas pequenas ou médias, inferiores a 1:100.000, porém, para escalas de maiores grandezas é necessário o uso de Modelos Digitais do Terreno (MDT) obtido de curvas de níveis de pequenas equidistâncias, a exemplo das contidas nas cartas topográficas 1:25.000. Tal precisão pode ser explicada pelos exaustivos e onerosos trabalhos que foram aplicados na elaboração dessas cartas topográficas, utilizando a aerofotogrametria de triangulação e um forte apoio técnico em solo para validar os dados coletados pelos sensores imageadores.

\section{Caracterização geológica e estrutural}

As duas sub-bacias hidrográficas estudadas têm como substrato geológico as rochas da Formação Barreiras, do Período Mioceno (ARAI, 2006). Para Guimarães e Bittar (2014), na parte superficial e mais plana da área ocorrem coberturas arenosas e areno-argilosas sobre as rochas da Formação Barreiras, oriundas dos processos intempéricos que agem sobre os Tabuleiros Litorâneos (Figura 2). Brito Neves et al. (2008), se referiu a esses sedimentos como uma Unidade Lito-Estratigráfica Informal, denominando-a de "Areias Brancas". Para esses autores são areias geralmente claras, uniformes, bem selecionadas, com menos de $20 \%$ de silte e argila, provavelmente provenientes de distintas fontes e processos.

$\mathrm{Na}$ figura 2 é possível observar que, em uma pequena área do baixo curso do rio Cascata, seu fluxo se dá sobre uma unidade litológica diferenciada, tratando-se das rochas cristalinas paleoproterozóicas do Complexo Cabaceiras (GUIMARÃES; BITTAR, 2014).

Após erodirem na parte superficial e entalharem seus vales sobre a Formação Barreiras, os rios em questão depositam seus sedimentos nas margens opostas da planície aluvial quaternária do rio Mamanguape. Nessa planície, os dois rios analisados possuem pequenas partes de seus canais até encontrarem o rio Mamanguape. Portanto, nas duas sub-bacias pesquisadas, há uma grande predominância das rochas sedimentares da Formação Barreiras.

Embora a área de estudo esteja dentro dos domínios de uma margem continental passiva, estudos realizados nas últimas décadas por Hasui (1990), Mabesoone e Alheiros (1993), Lima (2000), Brito Neves et al. (2004), Barbosa e Lima Filho (2006), Furrier et al. (2006), Brito Neves et al. (2008), Andrades Filho (2010), Bezerra (2011), Silva e Furrier (2013) e Bezerra et al. (2014) apresentaram uma série de evidências da existência de uma atuação considerável de atividades tectônicas, registradas na litologia, nas formas de relevo e, sobretudo, na hidrografia. 


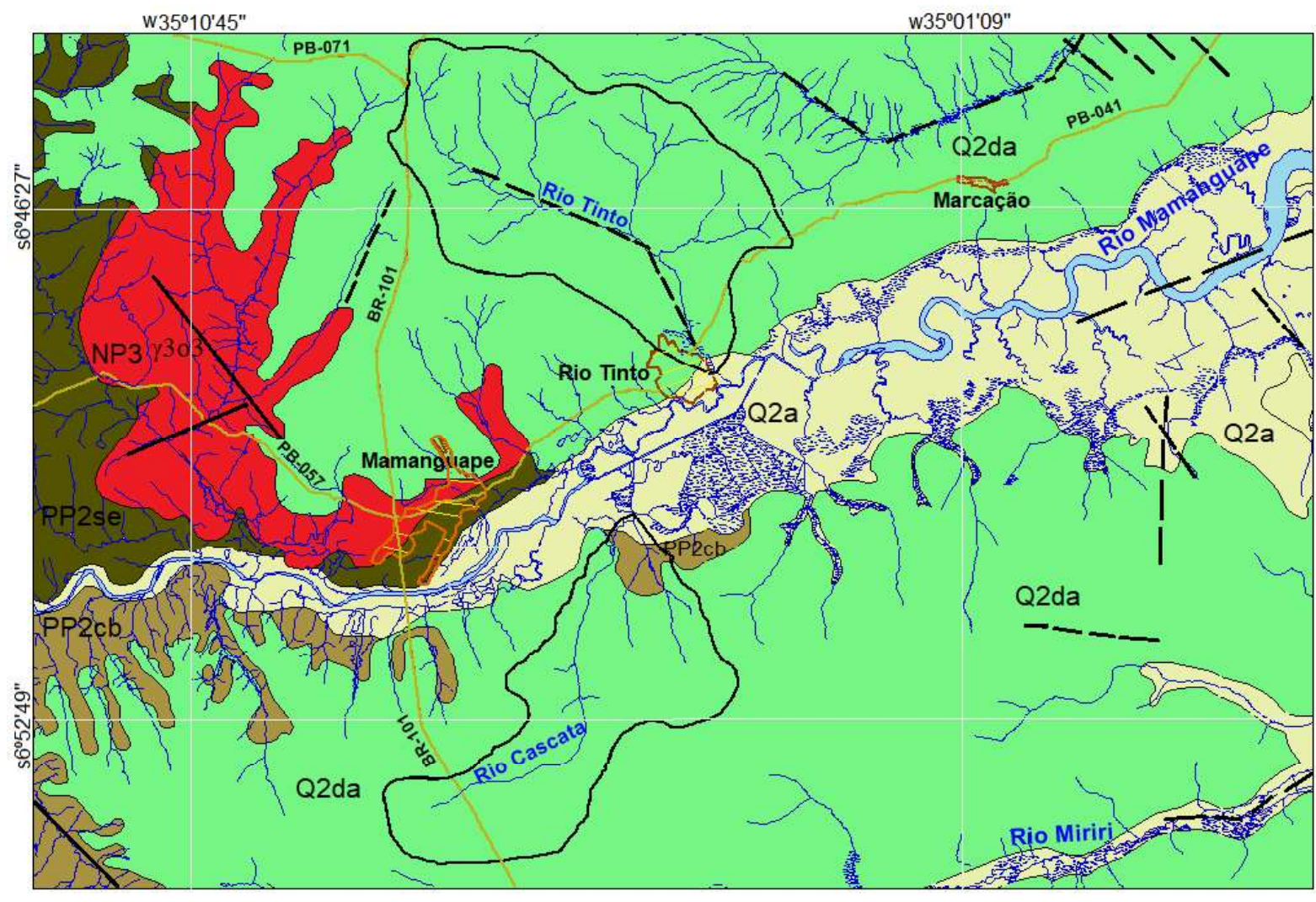

Q2a Depósitos aluvionares - Areias, cascalhos e níveis de argila.

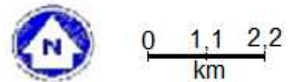

Q2da Depósitos arenosos e areno-argilosos: coberturas inconsolidadas arenosas a areno-argilosas, com granulometria variando de areia fina a muito grossa e grânulos dispersos; localmente pode apresentar níveis decascalhos e lentes de argila.

\section{Suíte Intrisuva Ouro Branco}

Muscovita-biotita monzogranitos a granodioritos, equigranulares a levemente porfiríticos médios a grossos, com fenocristais de plagioclásio, isotrópicos a levemente orientados. Possuem enclaves biotíticos, às vezes granada, xenólitos de paragnaisses migmatíticos, e às vezes estrutura fantasma. Suíte peraluminosa. U -P b por SHR IMP de $564 \pm 5 \mathrm{Ma}$

Complexo Sertânia

PP2se Granada-muscovita-biotita gnaisse, biotita gnaisse bandado, localmente migmatizados. Sheets de granitos leucocráticos peraluminosos. U - $\mathrm{P} \mathrm{b} \sim 2.0 \mathrm{Ga}$.

\section{Complexo Cabaceiras}

PP2cb Ortognaisses granodioríticos, tonalíticos e dioríticos, com niveis de anfibolito bandado a laminado, migmatizado. $\mathrm{U}-\mathrm{P}$ b variando de $2230 \pm 17 \mathrm{Ma}$ a $2164 \pm 16 \mathrm{Ma}$

- - Falha encoberta Falha ou fratura Sub-bacias hidrográficas estudadas

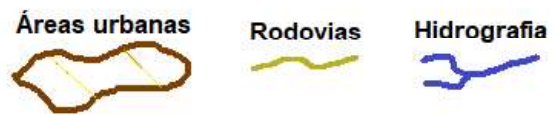

Figura 2 - Geologia da área das sub-bacias estudadas (Adaptado de Guimarães e Bitttar, 2014).

Bezerra e Vita-Finzi (2000) afirmaram que por meio de detecções em registros de poços, liquefação induzida por terremotos e datação de rochas de praia por radiocarbono, é possível estabelecer que dentro da margem passiva da placa sul-americana, nessa região, existem registros sísmicos estabelecidos, com ocorrência de terremotos pré-históricos do Holoceno com magnitude de até Ms> 6.8. Para Nogueira (2008), essa tensão regional seria provocada pela compressão gerada com o soerguimento da Cordilheira dos Andes de direção E-W e pelo arrasto da placa sulamericana.

Os estudos geomorfológicos de cunho morfoestrutural e morfotectônico são desenvolvidos no litoral do Nordeste brasileiro desde os trabalhos pioneiros elaborados nos Tabuleiros Litorâneos do Estado de Sergipe por Pontes (1969) e Leite (1973). Com o avanço das investigações foram incorporadas, em âmbito nacional, novas metodologias que utilizaram dados morfométri- 
cos para analisar a influência da estrutura geológica e da tectônica no relevo e na rede de drenagem.

Diversas deformações tectônicas foram observadas por Brito Neves et al. (2004), Brito Neves et al. (2009), Bezerra (2011) e Rosetti et al (2011a) na Formação Barreiras, com destaque para dois padrões principais, a sucessão de grabens e horsts e domos topográficos. Os trabalhos no âmbito da geomorfologia estrutural elaborados por Furrier et al. (2006) e Barbosa e Furrier (2015), obtiveram resultados que corroboram com afirmação dos autores supracitados, visto que deixaram evidente a existência tanto da configuração sequencial em grabens e horsts como a existência de estruturas dômicas nos Tabuleiros Litorâneos esculpidos sobre a Formação Barreiras no litoral paraibano.

\section{Procedimentos teórico-metodológicos}

Embora desde a década de 1990 já tenham sido desenvolvidos trabalhos de cunho morfoestrutural e morfométrico para a análise do relevo no Brasil (RODRIGUEZ; SUGUIO, 1992; TAKIYA, 1997), um dos trabalhos que teve maior repercussão foi o de Etchebehere et al. (2004), que analisou a região da bacia do Rio do Peixe, no Estado de São Paulo e constatou a atuação de tecptônica na configuração da bacia hidrográfica estudada.

Para esses autores, o termo "morfoestrutural" abrange as feições passivas, resultantes de uma deformação pretérita, nas quais a geometria dos cursos d'água podem se amoldar, fazendo com que o padrão local da rede de drenagem reflita a disposição dos corpos rochosos. Já o termo "morfotectônico", corresponde ao modelado do relevo no qual a acomodação dos elementos da rede de drenagem ocorre ao mesmo tempo das deformações crustais, estabelecendo, assim, um caráter "ativo" e simultâneo para as feições prenunciadas, que podem ser mensuradas por estudos morfométricos (SAADI, 1991). Entende-se que as feições morfoestruturais e morfotectônicas podem, dessa forma, ocupar grandes extensões territoriais ou áreas mais restritas, desde que estejam condicionadas a estrutura geológica na qual se desenvolveu (ROSS, 1992).

As metodologias que consideram a estrutura geológica e a morfometria para analisar as características do relevo vêm sendo cada vez mais utilizadas no mundo inteiro, a exemplo de Jordan (2003), na Hungria; Pereira et al. (2014), em Portugal; Kulkarni (2015), na
Índia; Furrier e Cuervo (2018), na Colômbia; Ivanov e Yermolaev (2018), na Rússia, visto que, podem revelar acontecimentos que não são explicados por análises puramente morfológicas e baseadas em eventos climáticos. Diversos autores têm chamado a atenção para esse fato desde a década de 1960 (VOLKOV et al., 1967; HACK, 1973; SEBEER; GORNITZ, 1983; ETCHEBEHERE et al., 2004; EL HAMDOUNI et al., 2008; ROSS 2013).

As análises morfométricas aplicadas ao estudo do relevo e da rede de drenagem que apresentam caráter estrutural podem identificar anomalias sugestivas de movimentações tectônicas recentes (GROHMANN et al., 2007; HARTWIG; RICCOMINI, 2010). Estas análises têm por finalidade a identificação preliminar de áreas com maior probabilidade de ocorrência nas estruturas tectônicas e devem anteceder os trabalhos de campo.

As anomalias nos canais de drenagem podem ser caracterizadas por mudanças locais abruptas na rede hidrográfica em relação aos padrões hidrográficos regionais. Elas podem ser desenvolvidas a partir de eventos tectônicos ou influências estruturais (HOWARD, 1967). Silva et al. (2006) apresentam como principais anomalias de drenagem os canais retilíneos, a existência de meandros comprimidos, canais com fundo de vales estreitos e/ou alargados com preenchimento aluviais, trechos embrejados por represamento natural, além de curvas acentuadas nos canais.

No presente artigo as análises foram realizadas através dos dados obtidos com a elaboração do material cartográfico e a aplicação de índices morfométricos. Foi necessário produzir três produtos cartográficos: o Modelo Digital do Terreno (MDT), o mapa de altimetria e o mapa de declividade. Os índices morfométricos aplicados foram Relação Declividade/Extensão (RDE), o índice Razão Fundo/Altura de Vale (RFAV) e o Fator Assimétrico (FA).

Em primeiro plano, as cartas topográficas 1:25.000 foram escaneadas e vetorizadas manualmente para extração dos atributos como curvas de nível, pontos cotados e rede de drenagem que posteriormente foram lançados no Software SPRING 5.4.3, para serem interpolados e gerar as informações cartográficas necessárias. A vetorização manual é uma tarefa árdua que demanda tempo na sua elaboração, porém, garante a extração fiel das informações contidas nas cartas.

Inicialmente foram verificadas as informações contidas no MDT e nos mapas confeccionados para entender o contexto morfológico da área em questão. 
O MDT foi gerado através da interpolação dos valores contidos nas curvas de nível e nos pontos cotados extraídos das cartas topográficas 1:25.000.

O mapa com as classes de altimetria foi elaborado com intervalos iniciais de $10 \mathrm{~m}$ até $30 \mathrm{~m}$; posteriormente foi lançado um intervalo de $30 \mathrm{~m}$ até atingir os $60 \mathrm{~m}$ e, a partir daí, a cada $40 \mathrm{~m}$, até o limite de $220 \mathrm{~m}$. Com o estabelecimento desses intervalos altimétricos pode-se visualizar com maior ênfase os desníveis de maior destaque no relevo, possibilitando a análise de possíveis configurações morfoestruturais e/ou morfotectônicas nas duas sub-bacias.

Para o mapa de declividades foram utilizadas as classes definidas pela Empresa Brasileira de Pesquisa Agropecuária (EMBRAPA, 2006). Inicialmente, tem-se os relevos planos e suaves ondulados, com desníveis topográficos muito pequenos e declividades de 0 a $8 \%$. O relevo ondulado possui superfície de topografia pouco movimentada com declives suaves de 8 a $20 \%$. No relevo forte ondulado ocorre uma superfície topográfica movimentada, com declives fortes de 20 a $45 \%$. O relevo montanhoso compreende superfície de topografia vigorosa e desnivelamentos relativamente grandes com declives de 45 a $75 \%$. E, por último, o relevo escarpado, onde ocorre predomínio de formas abruptas de declives muito fortes, usualmente ultrapassando $75 \%$.

Os padrões de declividade auxiliam no entendimento das relações entre a evolução do relevo e a rede de drenagem, visto que, regiões com intensa incisão dos canais fluviais por influência morfoestrutural ou morfotectônica, tendem a apresentar níveis de declividade mais acentuados e heterogêneos.

No contexto das análises morfométricas o índice Relação Declividade/Extensão (RDE) vem apresentando grande relevância. Na Geomorfologia, parâmetros morfométricos são utilizados de forma a viabilizar quantitativamente o ajuste das formas aos sistemas naturais. O índice RDE proposto por Hack (1973) permite a correlação do substrato litológico e a incidência de movimentações crustais na conformação de patamares ao longo dos canais fluviais (ETCHEBEHERE et al., 2004, ANDRADES FILHO, 2010; VALEZIO; PEREZ FILHO, 2014).

O estudo das informações contidas nos perfis longitudinais de rios das mais variadas extensões, cuja discussão remonta os trabalhos de Leopold e Wolman (1957), Hack (1957), Howard (1980), Christofoletti
(1981) entre outros, abordam a relação direta entre as variações de altimetria e de comprimento longitudinal do canal fluvial, da nascente à foz (VALEZIO; PEREZ FILHO, 2014).

Dessa forma é possível estabelecer se o processo de incisão que controla o desenvolvimento do canal está associado a alguma diferenciação litológica ou interferências tectônicas. Font e Lagarde (2010) reforçam que em áreas com baixas taxas de elevação os fluxos são caracterizados por valores de RDE mais baixos, enquanto os fluxos em áreas com taxas de elevação alta ou intermediária os valores desse índice são mais altos.

Para a determinação do RDE, inicialmente o índice é aplicado em segmentos selecionados pelo pesquisador nos canais fluviais $\left(\mathrm{RDE}_{\text {segmento }}-\mathrm{RDE}_{\mathrm{s}}\right)$ e, posteriormente, em sua totalidade ( $\mathrm{RDE}_{\text {total }}-\mathrm{RDE}_{\mathrm{t}}$ ) (Figura 3). Obtidos os resultados dessa primeira etapa, Martinez (2005) estabelece que o valor de $\mathrm{RDE}_{\mathrm{s}}$ deve ser dividido pelo $\mathrm{RDE}_{\mathrm{t}}$, sendo considerado com forte evidência de influência estrutural ou tectônica na sua configuração o trecho do canal que obtiver valor igual ou superior a 2 .

Na equação para obtenção do $\operatorname{RDE}_{\mathrm{s}}$ (Figura 3), $\Delta h$ representa a diferença altimétrica entre os dois pontos do segmento do canal em que o índice está sendo calculado, $\Delta l$ corresponde ao comprimento em metros do segmento analisado e $L$ é o comprimento total em metros do curso de água à montante do ponto médio para o qual o índice está sendo calculado. Na obtenção do $\mathrm{RDE}_{\mathrm{t}}, \Delta h$ é a diferença altimétrica total do curso estudado (cabeceira e a foz), In corresponde ao valor do logaritmo natural extraído de toda extensão do canal e $L$ é o comprimento total do canal em metros considerando sua sinuosidade.

O logaritmo natural representa uma correlação de evolução do canal fluvial em equilíbrio, como observado na fórmula (Figura 3), com a situação de evolução real do canal analisado. Dessa forma, os valores obtidos maiores que 2 (MARTINEZ, 2005) devem levar o pesquisador a analisar, em campo, possíveis desníveis (knickpoints) que podem ter, dentre outras causas, a influência direta de eventos tectônicos ou de heranças estruturais (HARTWIG; RICCOMINI, 2010).

Sebeer e Gornitz (1983) estabeleceram duas categorias de intensidades para os valores de RDE: os valores que caracterizam anomalias de $2^{\mathrm{a}}$ ordem, com valores de RDE iguais ou superiores a 2 e menores que 10 e os correspondentes a anomalias de $1^{\mathrm{a}}$ ordem, com valores iguais ou superiores a 10 . 


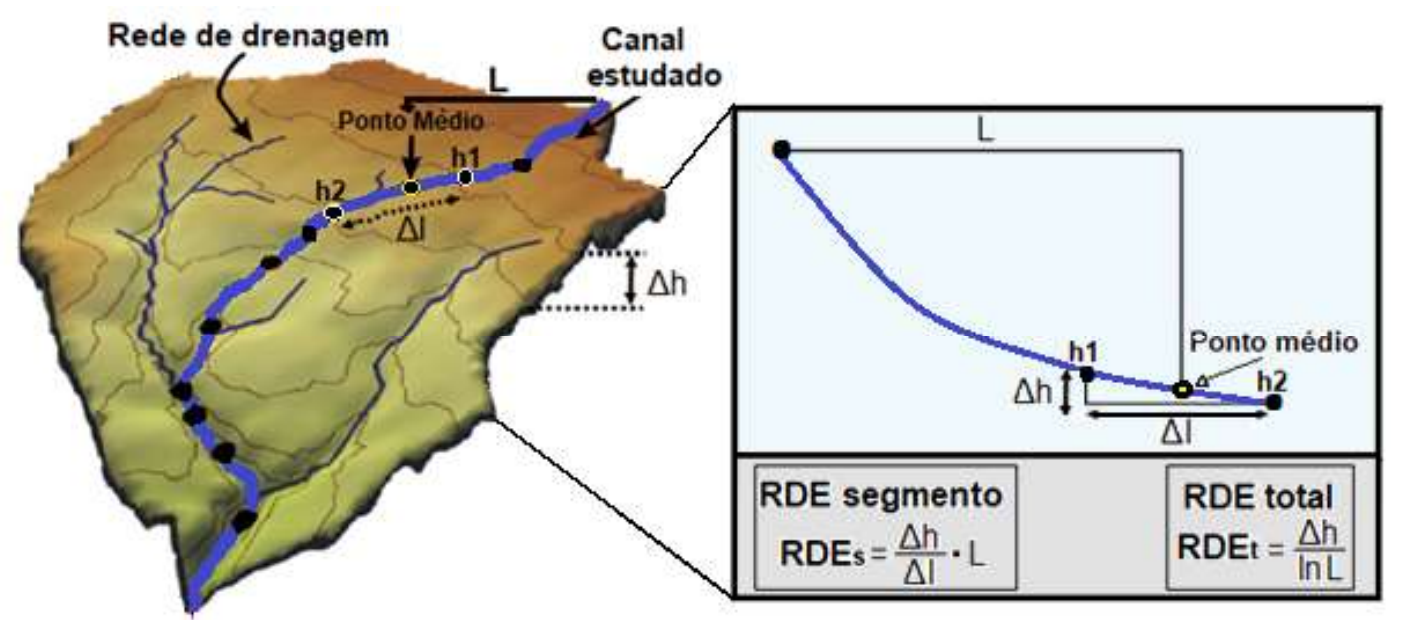

Figura 3 - Parâmetros do cálculo do indice RDE (adaptado de Font e Lagarde, 2010).

O índice Razão Fundo/Altura de Vale (RFAV) pode ser utilizado para investigar a razão entre o aprofundamento do canal fluvial e sua abrangência lateral, ou seja, a erosão de suas margens. Para Bull e McFadden (1977), o rio que estiver exercendo um aprofundamento acelerado do seu leito está sob influência do aumento da energia da corrente que pode ser resultado de soerguimentos por influência tectônica, porém, caso o rio esteja erodindo suas margens e estabelecendo certa sinuosidade ao canal, significa que o mesmo representa um fluxo em equilíbrio.

Diversos autores têm utilizado esse índice para avaliar transversalmente os canais fluviais, a exemplo de Barbosa (2013) (litoral sul do Estado da Paraíba); Silva e Girão (2016) (baixo curso do rio Capibaribe, Estado do Pernambuco) e Furrier e Cuervo (2018) (região de
Cartagena de Indias, Colômbia). As duas primeiras pesquisas foram desenvolvidas em áreas de margens passivas e a terceira em margem ativa, onde os valores de RFAV obtidos revelaram maior probabilidade de influência tectônica devido a uma maior incisão nos vales dos canais fluviais analisados.

Os valores mais baixos de RFAV são os que indicam maior desequilíbrio no canal fluvial (EL HAMDOUNI et al., 2008). Silva et al. (2003) revelam que valores baixos $(<1,0)$ representam vales em forma de $\mathrm{V}$, o que sugere que estão sob influência tectônica, enquanto que valores mais altos $(>1,0)$ são comuns em vales que apresentam forma de $U$, o que seria um indicativo de erosão lateral e estabilidade do canal. O cálculo desse índice pode ser efetuado através da equação que segue (Figura 4).

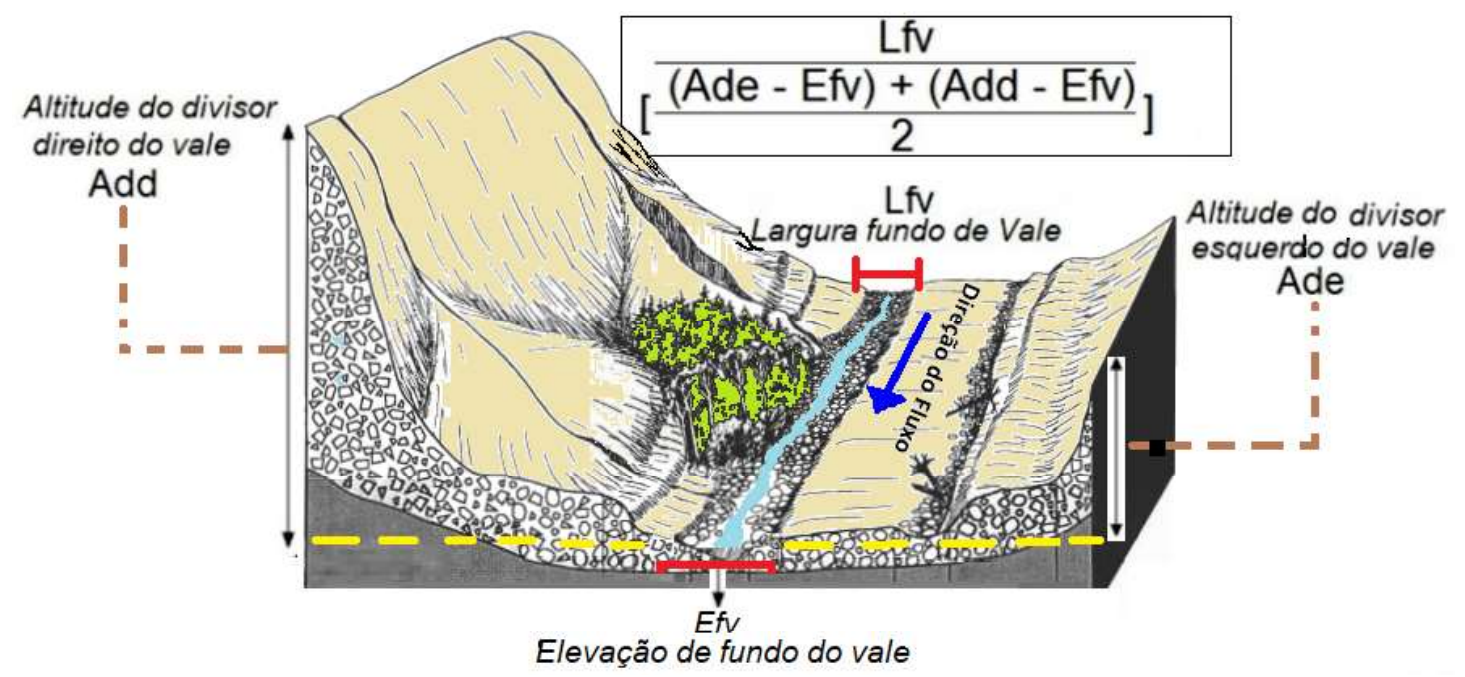

Figura 4 - Fórmula matemática e procedimentos de medida para obter os valores do índice RFAV (Adaptado de Grant e Swanson, 1995). 
$\mathrm{Na}$ equação, $L f v$ representa a largura do fundo de vale, Ade é a diferença altimétrica entre a cota do divisor de água esquerdo e a altura do fundo do vale, $A d d$ é a diferença altimétrica entre a cota do divisor de água direito e a altura do fundo do vale e $E f v$ é o valor da média de elevação do fundo do vale.

É válido lembrar que esse índice deve ser aplicado em litologia homogênea ou similar em ambos os lados e no leito do canal, visto que, rochas de diferentes tipos e consequentemente com resistências variadas podem estabelecer variações conspícuas nos atributos utilizados para a mensuração dos valores do RFAV.

$O$ índice Fator de Assimetria (FA) estabelece uma relação direta entre a localização do canal principal de um rio e a área total da bacia (Figura 5a). Logo, são consideradas assimétricas as bacias que apresentam canais principais deslocados de forma acentuada para direita ou para esquerda da área (Figura 5b). O Fator Assimétrico é definido pela seguinte equação (Figura $5 c)$ :

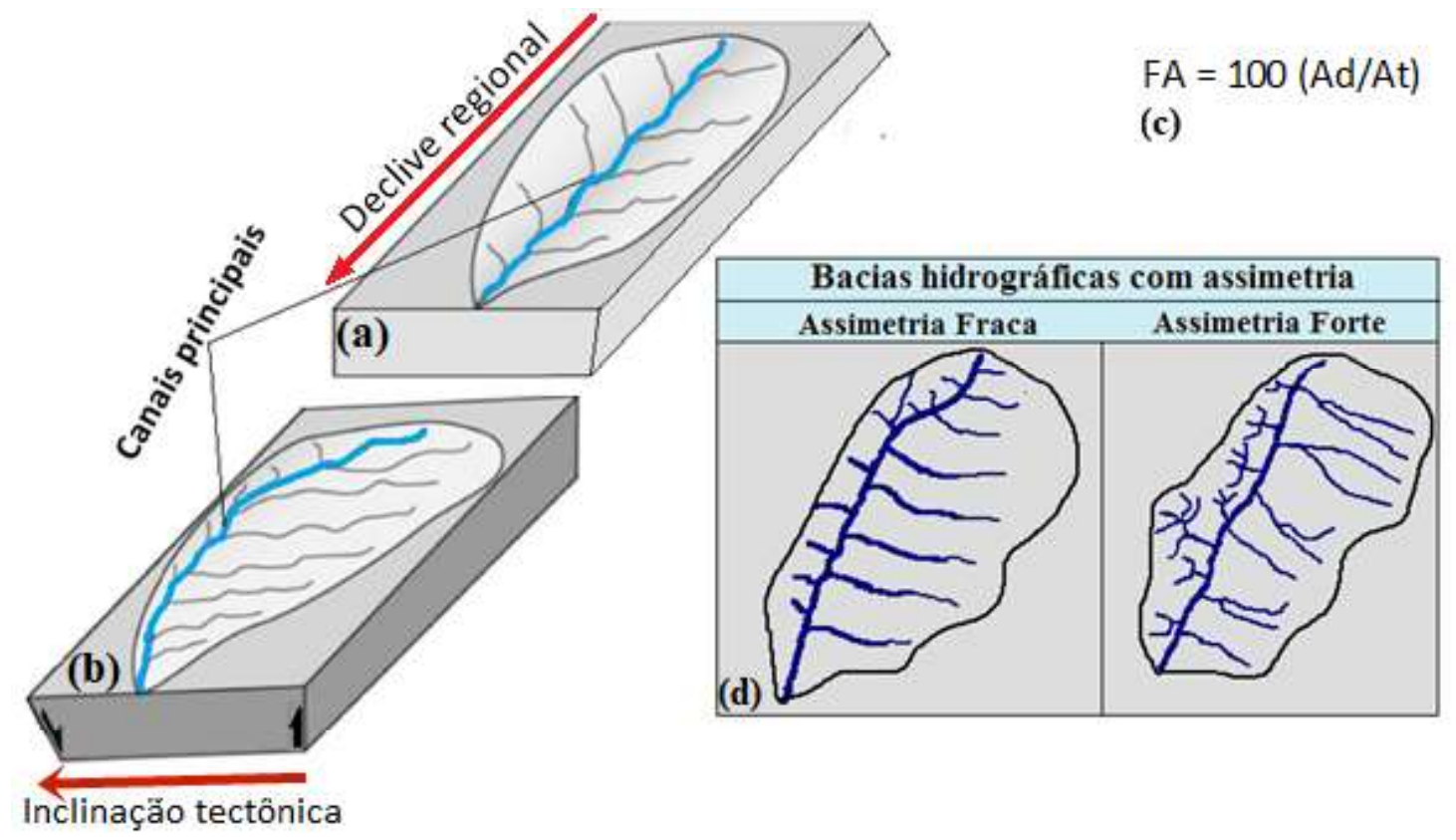

Figura 5 - Resposta da rede de drenagem ao soerguimento ao longo de uma linha de falha (Adaptado de Mahmood e Gloaguen, 2011 e Soares e Fiori, 1974).

$\mathrm{Na}$ fórmula, a expressão $F A$ corresponde ao Fator Assimétrico, $A d$ é a extensão territorial da área direita do rio e $A t$ corresponde a área total da bacia de drenagem. Soares e Fiori (1976) consideram que a presença de formas diferenciadas dos canais tributários de ambos os lados do canal principal reforça a intensidade da assimetria da bacia (Figura 5d).

Os valores de $F A$ próximos a 50 indicam que a bacia não sofreu influência tectônica considerável na sua configuração. No entanto, quando o valor é menor que 50 , pode indicar basculamento para a margem esquerda da bacia, e quando é maior que 50, para a margem direita da bacia (HARE; GARDNER, 1985; RINCÓN; VEGAS, 2000).

Em uma situação hipotética, se uma bacia tem 100 $\mathrm{km}^{2}$ de área total e apenas $30 \mathrm{~km}^{2}$ na margem direita do canal principal, significa que o valor de FA será 30 e o basculamento tectônico estará deslocado para a parte esquerda da bacia, que abrangerá $70 \mathrm{~km}^{2}$ da área total.

Andrades Filho (2010) estabeleceu classes de intensidades para o FA. Para esse autor a assimetria baixa corresponde a valores que se distanciaram 7 pontos, para mais ou para menos, do valor de equilíbrio 50, ou seja, 57 ou 43. Será considerada assimetria média, aquela na qual os valores variarem entre 7 e 15 pontos do valor de referência, ou seja, valores entre 57 e 65 ou entre 35 e 43. E, por fim, a assimetria alta, na qual o FA se distancia mais de 15 pontos do valor de referência. Portanto, uma bacia com FA $=67$ corresponde a uma assimetria alta com valor de 17 pontos, o que confere um basculamento para o lado direito da bacia, já que o valor é maior que 50 . 


\section{Resultados e discussões}

\section{Análise morfológica}

Morfologicamente, as duas sub-bacias estudadas apresentam características sugestivas de influência estrutural e tectônica na sua configuração. A sub-bacia do rio Tinto apresenta uma estruturação de canais de $4^{\text {a }}$ ordem, segundo a classificação Strahler (1952), com diferenças contundentes entre os tributários das margens direita e esquerda. Na sua margem esquerda estão os tributários maiores que atingem a $3^{\mathrm{a}}$ ordem de classificação, enquanto que na margem direita, ocorrem apenas pequenos canais de $1^{\mathrm{a}}$ ordem. Essa diferença entre os tributários de lados opostos do canal principal é entendida por Soares e Fiori (1976) como indício de atuação de atividade tectônica na configuração de bacias hidrográficas.

A sub-bacia do rio Cascata apresenta uma configuração morfológica diferenciada da sub-bacia do rio Tinto. Ela representa uma sub-bacia de $2^{\mathrm{a}}$ ordem, predominantemente com canais tributários de $1^{\mathrm{a}}$ ordem. De modo geral, nota-se um forte basculamento para sua margem direita e uma notável inflexão de canal no seu alto curso, que caracterizam influências de atividade tectônica. $\mathrm{O}$ fraco desenvolvimento dos canais fluviais pode ser atribuído às baixas altitudes do interflúvio dos rios Mamanguape $\mathrm{e}$ Miriri, que têm fortes indícios de se tratar de uma configu- ração estrutural em formas de teclado de piano, verificada por Furrier et al. (2006) como evidências de tectônica para os Tabuleiros Litorâneos no Estado da Paraíba.

\section{Análise morfométrica}

A análise morfométrica consiste em apresentar e discutir os valores obtidos com a aplicação dos índices morfométricos. A maioria dos resultados dos três índices revelaram possibilidades da atuação de atividade tectônica na configuração das sub-bacias estudadas.

\section{Índice Relação Declividade-Extensão (RDE)}

$\mathrm{Na}$ aplicação do RDE, primeiro foi verificado o valor do $\mathrm{RDE}_{\mathrm{t}}$, analisado para todo o canal principal dos rios. A escolha dos segmentos para aplicar o $\mathrm{RDE}_{\mathrm{s}}$ foi elaborada de forma subjetiva e aleatória, como sugerem McKeown et al. (1988). Os canais principais foram divididos em dois segmentos de extensões semelhantes para não haver disparidade nesse quesito (Figura 6). Os resultados apresentaram a necessidade de uma análise mais criteriosa em campo, visto que, revelaram valores sugestivos de atividade tectônica recente na configuração do perfil longitudinal dos rios (Tabela 1).
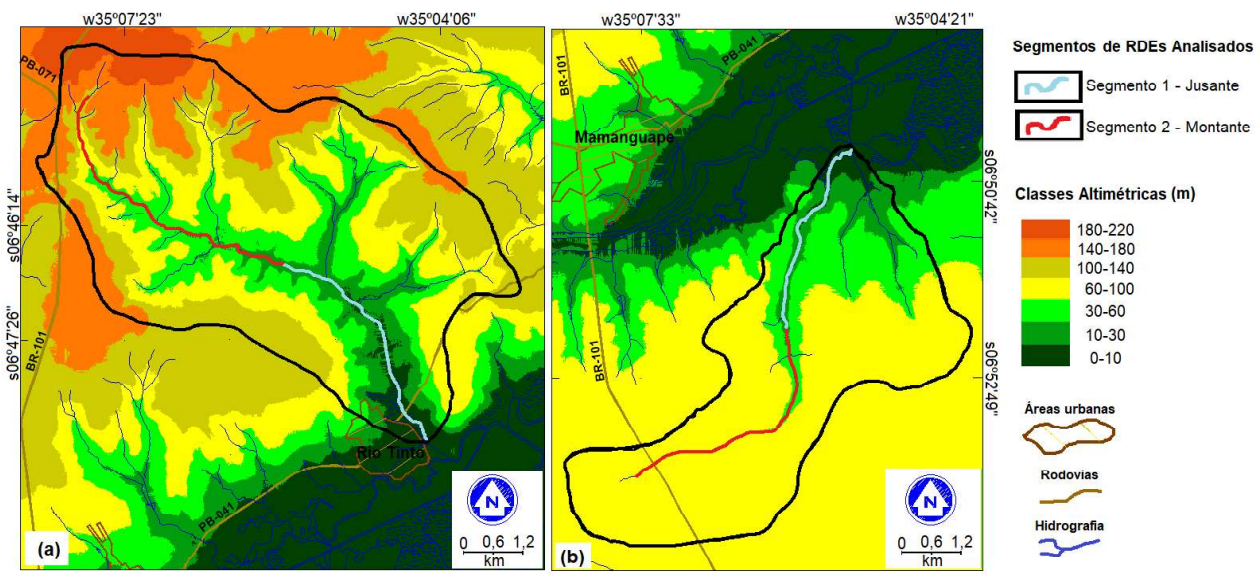

Figura 6 - Canais com segmentos selecionados para o cálculo do Índice de Relação Declividade/Extensão: (A) - Sub-bacia do rio Tinto, (B) - Sub-bacia do rio Cascata.

Tabela 1: Valores obtidos com a aplicação do índice RDE nas sub-bacias estudadas

\begin{tabular}{|c|c|c|c|c|}
\hline Sub-bacia Hidrográfica & RDES & RDEt & RDEs/RDEt & $\begin{array}{l}\text { Ordem de } \\
\text { anomalia }\end{array}$ \\
\hline Rio Tinto (Segmento 1-Jusante) & 31,4 & \multirow{2}{*}{16,7} & 1,87 & Sem Anomalia \\
\hline Rio Tinto (Segmento 2-Montante) & 58,6 & & 3,49 & 2 a ordem \\
\hline Rio Cascata (Segmento 1-Jusante) & 22,0 & \multirow{2}{*}{8,7} & 2,53 & $2^{a}$ ordem \\
\hline Rio Cascata (Segmento 2-Montante) & 30,8 & & 3,54 & 2a ordem \\
\hline
\end{tabular}


A jusante do canal principal do rio Tinto (Figura 6a), o primeiro segmento analisado, apresentou valores que não sugerem a atuação de atividade tectônica (Tabela 1). Tal segmento apresenta baixa diferenciação altimétrica entre seu ponto montante e jusante e está inserido em sua maior parte sobre as rochas sedimentares da Formação Barreiras que, nesse trecho, não apresenta desníveis bruscos, com variação altimétrica máxima de $20 \mathrm{~m}$ em um segmento de $5.519 \mathrm{~m}$ de extensão. É válido lembrar que o quesito analisado nesse trecho foi a configuração do perfil longitudinal do rio, sendo que esses resultados serão confrontados com os outros critérios avaliativos nos demais índices.

No segmento 2, à montante do rio Tinto, foi obtido o segundo maior valor de $\mathrm{RDE}_{\mathrm{s}} / \mathrm{RDE}_{\mathrm{t}}$ das duas sub-bacias estudadas $(3,49)$ (Tabela 2), caracterizando, assim, anomalia de $2^{\mathrm{a}}$ ordem, como sugerem Sebeer e
Gornitz (1983). Esse resultado é justificado pelo fato desse trecho apresentar um brusco desnível altimétrico que ocorre, principalmente, no alto curso do rio. Essa alteração de altimetria é da ordem de $95 \mathrm{~m}$ em um segmento de $5.590 \mathrm{~m}$, sendo que a maior diferenciação está concentrada nos $1.500 \mathrm{~m}$ iniciais na montante do canal.

$\mathrm{O}$ valor obtido sugere que a região apresenta erosão remontante acentuada no segmento em questão. Essa evidência é confirmada pela forte incisão que pode ser verificada no alto curso dessa sub-bacia, ao longo da rodovia BR-101, nas imediações de sua bifurcação com a rodovia PB-071 (Figura 7). Tal situação erosional é incompatível com um perfil de canal fluvial em equilíbrio e que apresenta homogeneidade litológica e climática, o que reforça a possibilidade desses valores serem representativos de desequilíbrio na configuração do canal por soerguimento tectônico regional dos tabuleiros litorâneos.

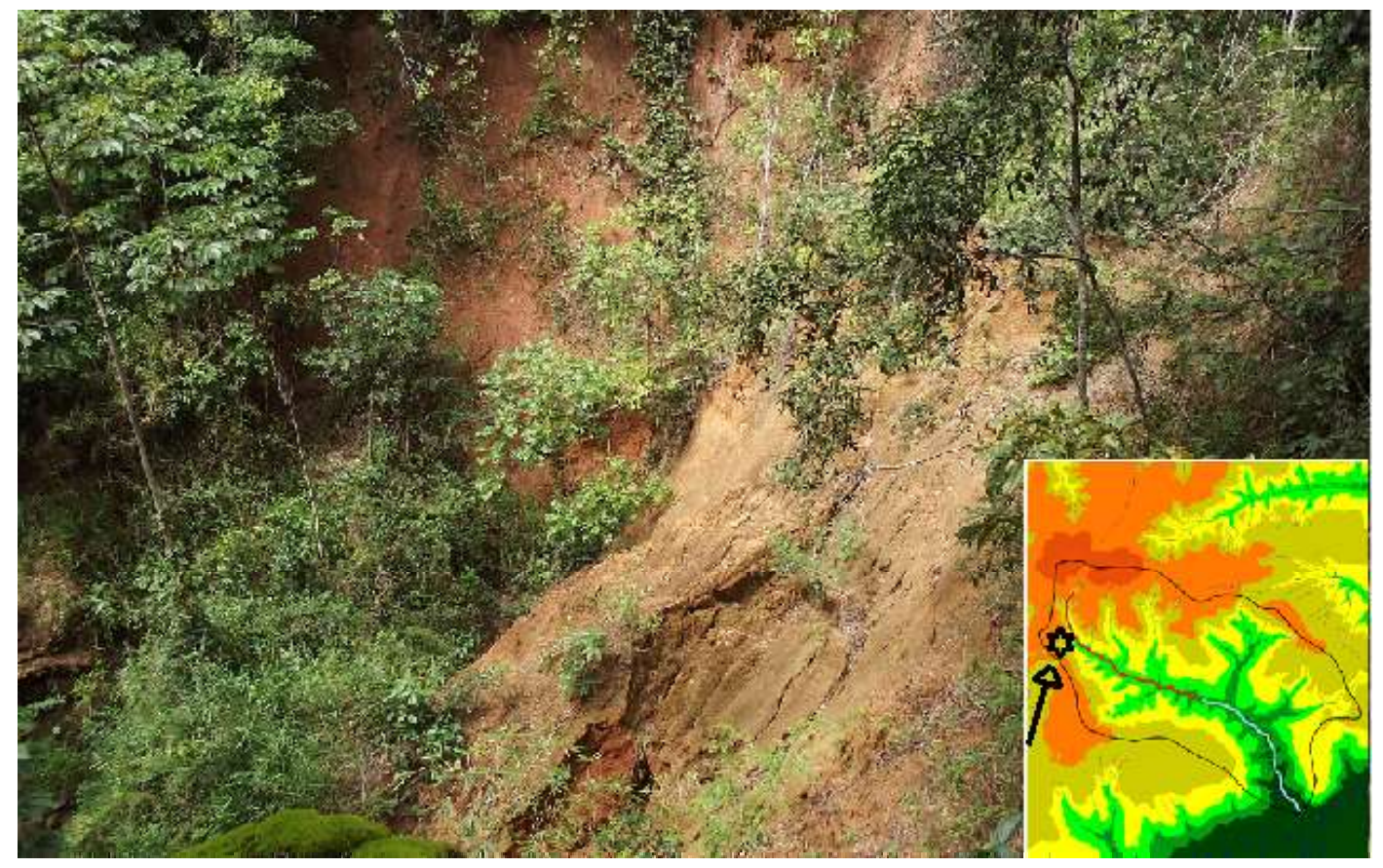

Figura 7 - Avanço da erosão remontante no alto curso da sub-bacia do rio Tinto. Fonte: Ivanildo Costa da Silva (2014).

Na sub-bacia do rio Cascata, os dois segmentos analisados (Figura 6b) demonstraram valores de $\mathrm{RDE}_{\mathrm{s}} /$ $\mathrm{RDE}_{\mathrm{t}}$ com anomalia de $2^{\mathrm{a}}$ ordem (Tabela 1). No segmento de jusante o valor obtido foi de 2,53. O desnível altimétrico total desse trecho foi calculado em $14 \mathrm{~m}$ em uma extensão do canal de $4.679 \mathrm{~m}$.

$\mathrm{O}$ valor da $\mathrm{RDE}_{\mathrm{s}} / \mathrm{RDE}_{\mathrm{t}}$ nesse segmento pode ser um indicativo de que as anormalidades são decorrentes da diferenciação litológica que ocorre no seu baixo curso (ver figura 2). Trata-se das rochas cristalinas do Complexo Floresta, as quais oferecem resistência diferenciada em relação as rochas sedimentares da Formação Barreiras, podendo, assim, desenvolver knickpoints que influenciam diretamente nos resultados de RDE, como sugere Andrades Filho (2010). É necessário que se faça uma investigação minuciosa nesse segmento em campo, para verificar o que influenciou esse valor de RDE elevado em uma área de baixa amplitude altimétrica, como sugerem Hartwig e Riccomini (2010). 
No segmento 2, à montante do rio Cascata, os valores de $\mathrm{RDE}_{\mathrm{s}} / \mathrm{RDE}_{\mathrm{t}}$ foram os maiores obtidos nesse estudo, chegando a 3,54 (Tabela 1). A variação altimétrica nesse trecho que está inserido totalmente sobre a litologia da Formação Barreiras é de $55 \mathrm{~m}$ em uma extensão de $5.044 \mathrm{~m}$. Esse resultado é indicativo de possível atuação tectônica na configuração do perfil longitudinal do rio, que pode ser justificado pela existência já comprovada de uma pequena cascata (knickpoints) localizada nesse segmento.

É possível notar ainda que o alto curso desse rio apresenta cotas que variam de 60 a 100 metros e, posteriormente, segue com queda acentuada para cotas que variam de 30 a 60 metros e, logo depois, novamente a altimetria diminui para cotas de 10-30 metros. Essas variações altimétricas acentuadas em pequenas extensões de canais fluviais influenciam os valores do índice RDE e podem estar associadas a soerguimentos tectônicos.

\section{Índice Razão Fundo/Altura de Vale (RFAV)}

Para analisar o comportamento do índice RFAV foram aplicados 3 perfis transversais em cada um dos dois canais principais das sub-bacias estudadas (Figura 8). Dos seis perfis analisados, quatro demonstraram valores compatíveis com a influência da atuação de atividade tectônica na incisão dos canais (Tabela 2).
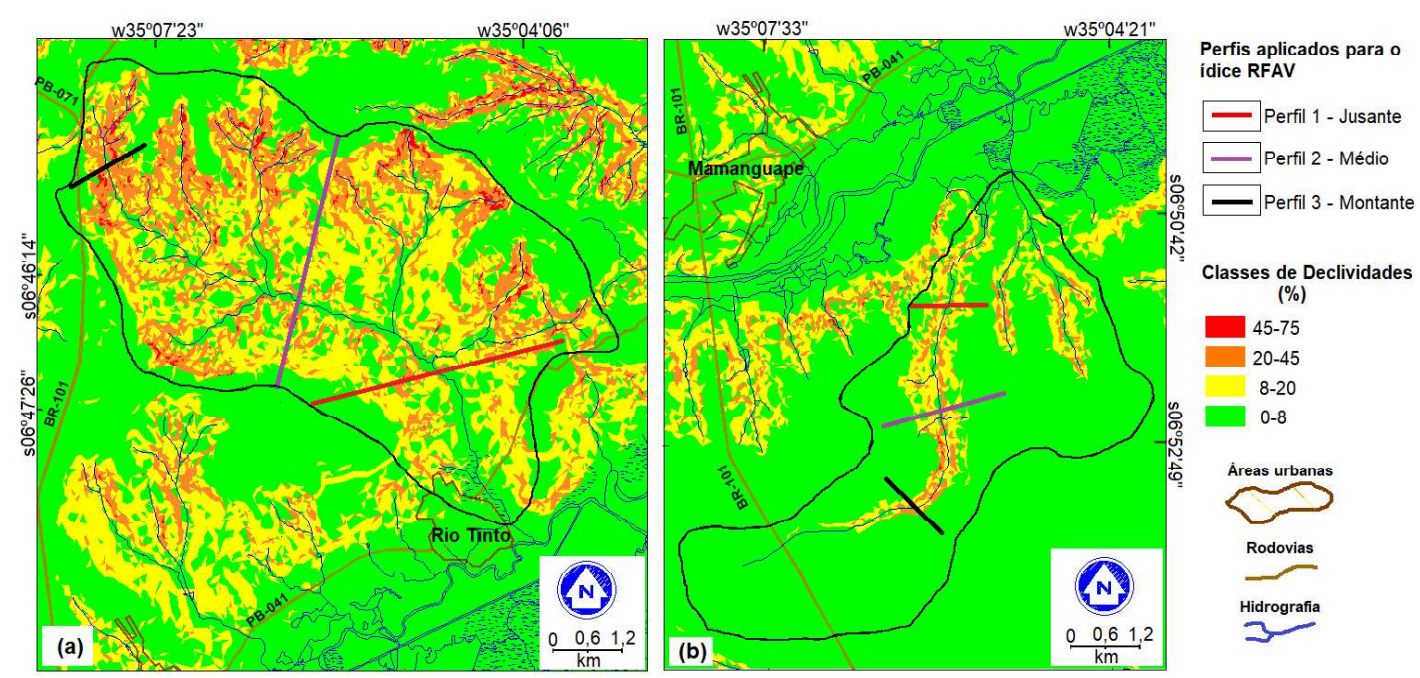

Figura 8-Perfis aplicados para o cálculo do índice Razão Fundo/Altura de Vale: (A) - Sub-bacia do rio Tinto, (B) - Sub-bacia do rio Cascata.

Tabela 2: Variáveis morfométricas e valores obtidos com aplicação do índice RFAV nas sub-bacias estudadas

\begin{tabular}{|c|c|c|c|c|c|}
\hline $\begin{array}{l}\text { Bacias e sub- } \\
\text { bacias } \\
\text { hidrográficas }\end{array}$ & $\begin{array}{l}\text { Largura do } \\
\text { fundo do } \\
\text { vale (m) }\end{array}$ & $\begin{array}{c}\text { Elevação } \\
\text { do divisor } \\
\text { esquerdo (m) }\end{array}$ & $\begin{array}{c}\text { Elevação } \\
\text { do divisor } \\
\text { direito (m) }\end{array}$ & $\begin{array}{l}\text { Elevação do } \\
\text { fundo do vale } \\
\text { (m) }\end{array}$ & RFAV \\
\hline Rio Tinto (1) & 114 & 125 & 102 & 11 & 1,11 \\
\hline Rio Tinto (2) & 82 & 170 & 129 & 26 & 0,66 \\
\hline Rio Tinto (3) & 45 & 171 & 144 & 60 & 0,44 \\
\hline Rio Cascata (1) & 25 & 51 & 46 & 10 & 0,64 \\
\hline Rio Cascata (2) & 33 & 84 & 73 & 30 & 0,72 \\
\hline Rio Cascata (3) & 34 & 86 & 84 & 60 & 1,36 \\
\hline
\end{tabular}

No perfil 1, aplicado a jusante do rio Tinto (Figura 8a), obteve-se valor de 1,11 , sugerindo assim que a incisão do canal, nesse ponto, não sofre influência tectônica na sua configuração como indicam Silva et al. (2003). Esse valor reforça o resultado de RDE obtido nesse segmento que também demonstrou não haver tal influência na configuração do perfil longitudinal. Dessa forma, pode-se inferir que a relação entre a incisão do canal principal e a sua erosão lateral nesse trecho do rio Tinto está em equilíbrio, tendendo a formar um vale em forma de $\mathrm{U}$. 
No perfil 2 (Figura 8a), os dados corroboram novamente com os resultados do RDE. Esse perfil foi aplicado no segmento médio do canal principal e revelou que ali ocorre uma incisão mais enérgica em relação à erosão lateral, representada pelo valor de RFAV de 0,66 , que sugere um soerguimento da área e uma resposta direta no canal pelo aumento do poder de incisão. A tendência nesse caso é a formação do canal em forma de $\mathrm{V}$, visto que o valor é inferior a 1 .

O perfil 3 (Figura 8a), a montante, apresentou o valor de RFAV de 0,44, o menor valor encontrado nesse estudo. Essa forte incisão do vale é compreensível, visto que, foi também nesse trecho que se obteve o maior valor de RDE na sub-bacia. Ali a energia de erosão ainda se mantém alta, sugerindo ser uma resposta ao soerguimento tectônico, já que os fatores litológicos e climáticos são homogêneos para todo o canal e não podem ser citados como causadores de tais variações morfométricas.

Nos três perfis do rio Cascata, dois apresentaram valores anômalos, indicativos de atividade tectônica (Tabela 2). Os perfis 1 e 2, aplicados na jusante e no segmento médio do canal, obtiveram valores de 0,64 e 0,72, respectivamente (Figura 8b). Esses dois trechos do canal principal apresentam duas variáveis que podem influenciar nos resultados desse índice: a ocorrência de knickpoints, formado por uma cascata no seu médio curso e a composição litológica diferenciada que controla o rio no seu baixo curso.

Dessa forma, o resultado obtido com a aplicação do perfil 1 pode ter relação com a variação litológica que ocorre na jusante do canal e o resultado do perfil 2 pode ser interpretado como um indício da atuação tectônica na área, visto que existe um knickpoints e o índice RDE já tinha apresentado resultado compatível com tal fato.

$O$ perfil 3 (Figura 8b) de RFAV não detectou influência tectônica à montante do canal do rio Cascata, onde o valor obtido foi de 1,36. Tal valor pode ser explicado pelo fato do rio, nos seus primeiros 2.800 metros, partindo da nascente, correr sobre uma área com desnível altimétrico muito baixo com menor poder de erosão e incisão do vale.

\section{Índice Fator Assimétrico (FA)}

O índice Fator de Assimetria reforçou a tendência tectônica que os demais índices já haviam sugerido nas sub-bacias analisadas (Figura 9). Os resultados mostraram que as duas sub-bacias apresentam assimetria alta (Tabela 3), considerando as intensidades propostas por Andrades Filho (2010).
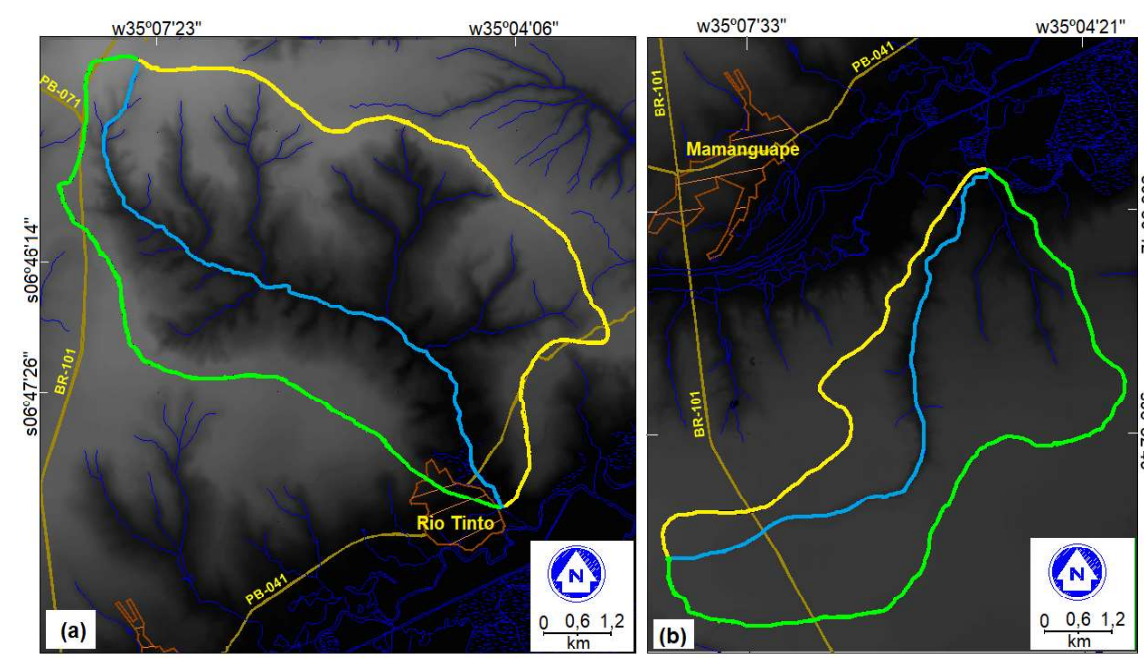

Parämentros utilizados no

indice FA
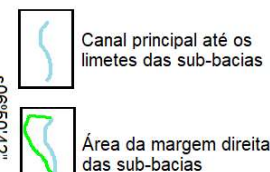

1 das sub-bacias

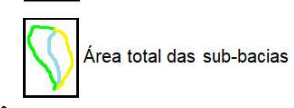

Figura 9-Parâmetros utilizados para o cálculo do índice Fator de Assimetria: (A) - Sub-bacia do rio Tinto, (B) - Sub-bacia do rio Cascata.

Tabela 3: Valores obtidos com a aplicação do índice FA nas sub-bacias estudadas

\begin{tabular}{lccccc}
\hline $\begin{array}{c}\text { Sub-bacia } \\
\text { Hidrográfica }\end{array}$ & $\begin{array}{c}\text { Área direita da } \\
\text { bacia }\left(\mathbf{k m}^{2}\right)\end{array}$ & $\begin{array}{c}\text { Área total da } \\
\text { bacia }\left(\mathbf{k m}^{2}\right)\end{array}$ & FA & $\mid$ FA -50| & $\begin{array}{c}\text { Classe de intensidade } \\
\text { da anomalia FA }\end{array}$ \\
\hline Rio Tinto & 13,67 & 40,05 & 34,13 & $-15,87$ & Alta \\
Rio Cascata & 19,86 & 26,88 & 73,88 & 23,88 & Alta \\
\hline
\end{tabular}


O índice FA obtido na sub-bacia do rio Tinto apresenta forte indício de basculamento tectônico para o lado esquerdo do canal principal. Esse indício pode ser analisado na figura 8a, na qual é possível verificar que os canais tributários mais imponentes surgem dessa margem, onde exercem uma forte incisão nos canais, em alguns casos superiores a 100 metros. Na tabela 2 é possível verificar, através das cotas mais elevadas extraídas para a aplicação do índice RFAV, o caráter soerguido da margem esquerda dessa sub-bacia.

Como questões climáticas ou litológicas não podem ser responsabilizadas por gerar tal assimetria na área estudada, resta supor que a mesma é resultado de eventos tectônicos, como também ocorre na sub-bacia do rio Cascata, que apresentou um valor de FA ainda maior, de 73,88, compatível com valores obtidos por Furrier e Cuervo (2018) em área de margem continental ativa na região de Cartagena de Indias, Colômbia.

$\mathrm{O}$ valor de FA maior que 50, a exemplo do que foi constatado na sub-bacia do rio Cascata, indica que o basculamento se dá para o lado direito, como pode ser verificado na figura $8 \mathrm{~b}$. Essa área, embora disponha de altimetria modesta, apresenta evidências conspícuas de influência tectônica na sua configuração, fato reafirmado fortemente pelos demais valores obtidos através dos índices morfométricos aplicados.

\section{Considerações Finais}

As ferramentas e as metodologias empregadas nesse trabalho se mostraram bastante eficientes no estabelecimento de padrões anômalos tanto do relevo como da rede de drenagem nas sub-bacias estudadas. Os produtos cartográficos e os valores obtidos com índices morfométricos demonstraram que a configuração atual do relevo e da rede de drenagem não condizem com um desenvolvimento impulsionado, meramente, por influências climáticas, tendo indicativos contundentes da influência estrutural e tectônica nesse processo.

Essa influência é evidenciada pelos fortes basculamentos observados nos mapas e também corroborados pelos valores obtidos através do índice FA; alta incisão dos vales, que são superiores a erosão lateral, representada pelos valores obtidos com a aplicação do índice RFAV e a existência de knickpoints, que influenciaram nos valores obtidos com o índice RDE. Esses resultados obtidos com a análise do relevo e da rede de drenagem são coincidentes com as observações geológicas de Bri- to Neves et al. (2004) e Brito Neves et al. (2008), que relacionaram tais anomalias na região à existência de falhas normais, sobretudo atribuídas ao processo de reativação de antigas zonas de cisalhamento no Terciário.

Neste trabalho os resultados alcançados foram, ainda, compatíveis e proporcionais a outros estudos morfométricos realizados em outras partes do Brasil e até mesmo em trabalhos realizados em margem continental ativa. Embora os valores dos resultados obtidos em margem continental ativa sejam de intensidade maior.

Os valores obtidos com a aplicação desses índices nas duas sub-bacias demonstraram que suas estruturações morfológicas, sofreram em período recente, movimentações e/ou ajustamentos tectônicos que alteraram significativamente suas variáveis morfométricas. Tal fato indica a necessidade de desenvolvimento de novas pesquisas em outras áreas da borda oriental brasileira para revalidar os valores aqui obtidos. Os resultados desta pesquisa, assim como os outros resultados apresentados oriundos de outros pesquisadores reforçam que a influência estrutural e tectônica na configuração do relevo e da rede de drenagem não podem mais ser renegadas em estudos de caráter geomorfológico na borda oriental brasileira.

\section{Referências Bibliográfica}

ANDRADES FILHO, C. O. Análise morfoestrutural da porção central da bacia Paraíba (PB) a partir de dados MDE-SRTM e ALOS-PALSAR FBD. Dissertação (Mestrado em Sensoriamento Remoto). Instituto Nacional de Pesquisas Espaciais - INPE, São José dos Campos, 2010. 150p.

ARAI, M. A grande elevação eustática do Mioceno e sua influência na origem do Grupo Barreiras. Geol. USP, Sér. Cient., São Paulo, v. 6, n. 2, p. 1-6, 2006.

BARBOSA, A.; LIMA FILHO, M. Aspectos estruturais e estratigráficos da faixa costeira Recife-Natal: observações em dados de poços. Boletim de Geociências da Petrobras, Rio de Janeiro, v. 14, n. 1, p. 287-306, maio 2006.

BARBOSA, M. E. F. Geomorfologia e tectônica da Folha Jacumã 1:25.000. Dissertação (Mestrado em Geografia). Programa de Pós-Graduação em Geografia, Universidade Federal da Paraíba, João Pessoa, 2013. 117p.

BARBOSA, M. E. F.; FURRIER, M. Caracterização geomorfológica e morfométrica para averiguação de atividade tectônica. Mercator, v. 14, n. 3, p. 123-149, 2015. 
BEZERRA, F. H. R. Deformação tectônica na Formação Barreiras: exemplos das Bacias Potiguar e Paraíba, Brasil. In: XIII Congresso da Associação Brasileira de Estudos do Quaternário (ABEQUA), 13., 2011, Rio de Janeiro. Anais... Rio de Janeiro. 2011.

BEZERRA, F. H. R.; ROSSETTI, D. F.; OLIVEIRA, R. G.; MEDEIROS, W. E.; BRITO NEVES, B. B.; BALSAMO, F.; NOGUEIRA, F. C. C.; DANTAS, E. L.; ANDRADES FILHO, C.; GÓES, A.M. Neotectonic reactivation of shear zones and implications for faulting style and geometry in the continental margin of NE Brazil. Tectonophysics, n. 614, p.78-90, 2014.

BEZERRA, F. H. R.; VITA-FINZE, C. How active is a passive margin? Paleoseismicity in northeastern Brazil. Geology, v. 28, n. $7,2000$.

BRITO NEVES, B. B.; ALBUQUERQUE, J. P. T.; COUTINHO, J. M. V.; BEZERRA, F. H. R. Novos Dados Geológicos e Geofísicos para a caracterização geométrica e estratigráfica da Sub Bacia de Alhandra (SE Paraíba). Geologia USP. Série Científica, v. 9, p. 63-87, 2009.

BRITO NEVES, B. B.; MANTOVANI, M. S. M.; MORAES, C. F.; SIGOLO, J. B. As anomalias geológicas e geofísicas da área norte de Itapororoca-PB, Folha Guarabira. Revista Brasileira de Geociências, v. 38, n. 1, p. 1-23, 2008.

BRITO NEVES, B. B.; RICCOMINI, C.; FERNANDES, T. M. G.; SANT'ANNA, L. G. O Sistema Tafrogênico Terciário do Saliente Oriental Nordestino na Paraíba: um Legado Proterozóico. Revista Brasileira de Geociências, 34 (1), p. 127-134, 2004.

BULL, W. B.; MCFADDEN, L. D. Tectonic geomorphology north and south of the Garlock fault, California. In: VIII Geomorphology Symposium-Geomorphology in Arid Regions, 8., 1977, Binghamton. Anais... Binghamton: Doehring, D.O., 1977. p. 115-138.

CHRISTOFOLETTI, A. Geomorfologia Fluvial. São Paulo: Edgard Blucher, 1981. 314p.

EL HAMDOUNI, R.; IRIGARAY, C.; FERNÁNDEZ, T.; CHACÓN, J.; KELLER, E. A. Assessment of relative active tectonics, southwest border of the Sierra Nevada (Southern Spain). Geomorphology, v. 96, n. 2, p. 150-173, 2008.

EMBRAPA. Centro Nacional de Pesquisa de Solos (Rio de Janeiro, RJ). Sistema brasileiro de classificação de solos. 2 . ed. - Rio de Janeiro: EMBRAPA-SPI, 2006.

ETCHEBEHERE, M. L. C.; SAAD. A. R.; FULFARO, V. J.; PERINOTTO, J. A. J. Aplicação do Índice Relação Declividade-
Extensão - RDE na bacia do Rio do Peixe (SP) para detecção de deformações neotectônicas. Revista do Instituto de Geociências - USP, v. 4, n. 2, p. 43-56, 2004.

FONT, M.; AMORESE, D.; LAGARDE, Jean-Louis. DEM and GIS analysis of the stream gradient index to evaluate effects of tectonics: The Normandy intraplate area (NW France). Geomorphology, n.119, p.172-180, 2010.

FURRIER, M.; ARAÚJO, M. E.; MENESES, L. F. de. Geomorfologia e tectônica da Formação Barreiras no estado da Paraíba. Geol. USP Sér. Científica, v. 6, n. 2, p. 61-70, out. 2006.

FURRIER, M.; CUERVO, G. V. Geomorfologia estrutural, morfotectônica e morfometria da folha Cartagena 1:100.000 Colômbia. Cuadernos de Geografía: Revista Colombiana de Geografía, v. 27, n. 1, p. 67-86, 2018.

FURRIER, M.; NÓBREGA, W. R.; SOUZA, A. S. Análise morfométrica e morfotectônica do gráben do rio Mamanguape e adjacências, borda oriental do estado da Paraíba, Brasil. Revista do Departamento de Geografia - USP, v. 28, p. 25-38, 2014.

GRANT, G. E.; SWANSON, F. J. Morphology and processes of valley floors in mountain streams, Western Cascades, Oregon. Geophys. Monogr. Ser., v. 89, p. 83-101, 1995.

GROHMANN, C. H.; RICCOMINI, C.; ALVES, F. M. SRTMbased morphotectonic analysis of the Poços de Caldas, Alkaline Massif, southeastern Brazil. Computers \& Geosciences, v.33, p.10-19, 2007.

GUimarÃes, I. P.; BITTAR, S. M. B. Mapa geológico: folha Guarabira SB.25-Y-A-V. Recife: CPRM, 2014. Escala $1: 100.000$.

HACK, J. T. Stream-profile analysis and stream-gradient index. Journal Research U.S. Geol. Survey, v. 1, n. 4, p. 421-429, 1973.

HACK, J. T. Studies of longitudinal stream profiles in Virginia and Maryland. In: U.S. Geol. Survey Prof. Paper, 294-B, p. 45-97, 1957.

HARE, P. W.; GARDNER, I. W. Geomorphic indicators of vertical neotectonism along converging plate margins, Nicoya Peninsula, Costa Rica. In: MORISAWA, M.; HACK, J.T. (Eds.) Tectonic geomorphology:proceedings of the 15th Annual Geomorphology Symposia Series. Binghamton, p. 76-104, 1985.

HARTWIG, M. E.; RICCOMINI, C. Análise morfotectônica da região da Serra dos Órgãos, Sudeste do Brasil. Revista Brasileira de Geomorfologia, v.11, n.1, p.11-20, 2010. 
HASUI, Y. Neotectônica e aspectos fundamentais da Tectônica Ressurgente no Brasil. Boletim da Sociedade Brasileira de Geologia - Núcleo Minas Gerais, n.11, p.1-32, 1990.

HESSEL, M. H.; BARBOSA, J. A. Moluscos Neocretácicos da Região de Pedro Velho - Canguaretama (RN), Bacia Potiguar. Estudos Geológicos, v. 15. 2005

HOWARD, A. D. (1980). Thresholds in river regimes. In: COATES, D. R.; VITEK, J. D. Thresholds in Geomorphology. Allen and Unwin: Winchester.

HOWARD, A. D. Drainage analysis in geologic interpretation: a summation. American Association of Petroleum Geologie Bulletim. v. 51, n. 11, p. 2246-2259, 1967.

IVANOV, M. A.; YERMOLAEV, O. P. Capability of applying morphometric parameters of relief in river basins for geomorphological zoning of a territory. Earth and Environmental Science, n. 107, 2018.

JORDAN, G. Morphometric analysis and tectonic interpretation of digital terrain data: a case study. Earth Surface Processes and Landforms, n.28, p.807-822, 2003.

KULKARNI, M. D. The Basic Concept to Study Morphometric Analysis of River Drainage Basin: A Review. International Journal of Science and Research, v.4, p. 2277-2280, 2015.

LEITE, L. W. Geomorfologia dos tabuleiros costeiros de Sergipe. In: XXVII Congresso Brasileiro de Geologia, 27., 1973. Aracaju. Anais... Aracaju: SBG, 1973. p. 373-384.

LEOPOLD, L. B.; WOLMAN, M. G. (1957). River Channel Patterns: Braided, Meandering and Straight. In: Geological Survey Professional Paper 282-B. United States Government Printing Office, Washington.

LIMA, C. U. O Neotectonismo na costa do Sudeste e do Nordeste Brasileiro. Revista de Ciência e Tecnologia, n. 15, p. 91-102, 2000.

LIMA, V. F. Estudo neotectônico e geomorfológico em Margem Continental Passiva: um estudo de caso na carta topográfica Rio Mamuaba 1:25.000. Dissertação (Mestrado em Geografia) - Programa de Pós-Graduação em Geografia, Departamento de Geociências, Centro de Ciências Exatas e da Natureza, Universidade Federal da Paraíba, João Pessoa, 2016. $117 \mathrm{p}$.

MABESOONE, J. M.; ALHEIROS, M. M. Evolution of the Pernambuco-Paraíba-Rio Grande do Norte Basin and the problem of the South Atlantic connection. Geologie en Mijnbouw. n. 71, p.351-362, 1993.
MAHMOOD, S. A.; GLOAGUEN, R. Appraisal of active tectonics in Hindu Kush: insights from DEM derived geomorphic indices and drainages analysis. Geoscience Frontiers, v. 3, n. 4, p. 407-428, 2012.

MARTINEZ, M. Aplicação de parâmetros morfométricos de drenagem na bacia do Rio Pirapó: o perfil longitudinal. Dissertação (Mestrado em Geografia) - Departamento de Geografia do Centro de Ciências Humanas, Letras e Artes, Universidade Estadual de Maringá, Maringá, 2005. 96p.

MCKEOWN, F. A.; JONES-CECIL, M.; ASKEWCB, L.; MCGRATH, M. B. Analysis of stream-profile data and inferred tectonic activity, eastern Ozark Mountains region. U.S. Geological Survey Bulletin, n. 1807, p. 1-39, 1988.

NOGUEIRA, F. C. C. Estruturas tectônicas cenozoicas na porção leste da Bacia Potiguar. Tese. Programa de PósGraduação em Geodinâmica e Geofísica, Universidade Federal do rio Grande do Norte, Natal-RN, 2008. 136p.

PEREIRA, D. M. I.; PEREIRA, P. J. S.; SANTOS, L. J. C.; SILVA, J. M. F. Unidades geomorfológicas de Portugal Continental. Revista Brasileira de Geomorfologia, v.15, n.4, p.567-584, 2014.

PONTES, F. C. Estudo morfoestrutural da Bacia SergipeAlagoas. Boletim Técnico da PETROBRÁS. Rio de Janeiro, v.12, n.3. 1969.

RINCÓN, P. J.; VEGAS, R. Aplicación de índices geomorfológicos de actividad tectónica reciente en el antepaís bético. Geogaceta, Salamanca (Spain), v. 27, p. 139-142, 2000.

RODRIGUEZ, S. K.; SUGUIO, K. Gradientes hidráulicos das drenagens de $2^{\text {a }}$ ordem: uma contribuição para os estudos de neotectônica da "Volta Grande" do rio Xingu, Altamira - PA. In: XXXVII Congresso Brasileiro de Geologia, 37., 1992. São Paulo. Anais... São Paulo: SBG, 1992. p. 598-600.

ROSS, J. L. S. O registro dos fatos geomórficos e a questão da taxonomia do relevo. Revista do Departamento de Geografia da FFLCH/USP, n. 6, p. 17-29, 1992.

ROSS, J. L. S. O relevo brasileiro nas macroestruturas antigas. Revista Continentes (UFRRJ), n.2, p. 8-27, 2013.

ROSSETTI, D. F.; BEZERRA, F. H. R.; GÓES, A. M. ; VALERIANO, M. M. ; ANDRADE-FILHO, D. O.; MITTANI, J. C. R.; TATUMI, S. M.; BRITO NEVES, B. B. Late Quaternary sedimentation in the Paraiba Basin, Northeast Brazil: Landform, sea level and tectonics in Eastern South America passive margin. Palaeogeography, Palaeoclimatology, Palaeoecology, v. 300, p. 191-204, 2011a. 
ROSSETTI, D. F.; BEZERRA, F. H. R.; GÓES, A. M.; BRITO NEVES, B. B. Sediments deformation and post-Miocene Strata, Northeast Brazil: Evidence for paleoseismicity in a passive margin. Sedimentary Geology, v. 235, p. 172-187, 2011 b.

SAADI, A. Ensaio sobre a morfotectônica de Minas Gerais. Belo Horizonte. Tese de Professor Titular, Programa de PósGraduação em Geografia, Universidade Federal de Minas Gerais, Belo Horizonte. 1991. 285p.

SANTOS, V. C. Ambientes de confluência no contexto da rede de drenagem: Exemplo da bacia hidrográfica do rio Ivaí - Estado do Paraná. Tese (Doutorado em Geociências e Meio Ambiente). Instituto de Geociências e Ciências Exatas, Universidade Estadual Paulista, Rio Claro. 2015. 458p.

SEBEER, L.; GOMITZ, V. River profiles along the Himalayan arc as indicators of active tectonics. Tectonophysics, n. 92, p. 335-367, 1983.

SILVA, A. C.; GIRÃO, O. Identificação de influências neotectônicas através de imagens SRTM, a partir da morfometria do baixo curso do rio Capibaribe-PE. Revista de Geologia, v. 29, n.2, p.213-225, 2016.

SILVA, I. C. Geomorfologia, hidrografia e tectônica da folha Araçaji 1:25.000, estado da Paraíba. Dissertação (Mestrado em Geografia). Programa de Pós-Graduação em Geografia, Departamento de Geociências, Centro de Ciências Exatas e da Natureza, Universidade Federal da Paraíba, João Pessoa, 2014. $139 \mathrm{p}$.

SILVA, I. C.; FURRIER, M. Análise de parâmetros físicos, morfológicos e morfométricos para avaliação de influência neotectônica nas bacias dos riachos Timbó e Marmelada, afluentes do rio Itapororoca/PB. Cadernos de Geociências, v. 10, n. 1, p. 23-33, 2013.

SILVA, P. G.; GOY, J. L.; ZAZO, C.; BARDAJÍ, T. Faultgenerated mountain fronts in southeast Spain: geomorphologic assessment of tectonic and seismic activity. Geomorphology, v. 50, n. 1 , p. $203-225,2003$.

SILVA, T. M.; MONTEIRO, H. S.; CRUZ, M. A.; MOURA, J. R. S. Anomalias de Drenagem e Evolução da Paisagem no Médio Vale do Rio Paraíba do Sul (RJ/SP). Anuário do Instituto de Geociências - UFRJ, v. 29, n. 2, p. 210-224, 2006.

SOARES NETO, G. B. Método de classificação semiautomático das unidades básicas de relevo em regiões tropicais. Tese de Doutorado, Instituto de Geociências, Universidade de Brasília, Brasília-DF, 2015. 103p.

SOARES, P. C.; FIORI, A. P. Lógica e sistemática na análise e interpretação de fotografias aéreas em geologia. Notícia Geomorfológica. Campinas, v. 16, n. 32, p. 71-104, 1976.

TAKIYA, H. Estudo da sedimentação neogênico-quaternária no município de São Paulo: caracterização dos depósitos e suas implicações na geologia urbana. Tese (Doutorado) Instituto de Geociências, Universidade de São Paulo, São Paulo. 1997. 152p.

VALEZIO, E.V.; PEREZ FILHO, A. Anomalias no rio Jacaré Pepira (SP) e sua correlação lito estrutural. In: Simpósio Nacional de Geomorfologia, 2014, Manaus. Anais... Manaus-AM, 2014.

VOLKOV, N. G.; SOKOLOVSKY, I. L.; SUBBOTIN, A. I. Effect of recent crustal movements on the shape of longitudinal profiles and water levels in rivers. In: International Symposium on River Mechanics, 1967. Bern. Proceedings... Bern: International Union of Geodesy and Geophysics, p. 105-116. 1967. 